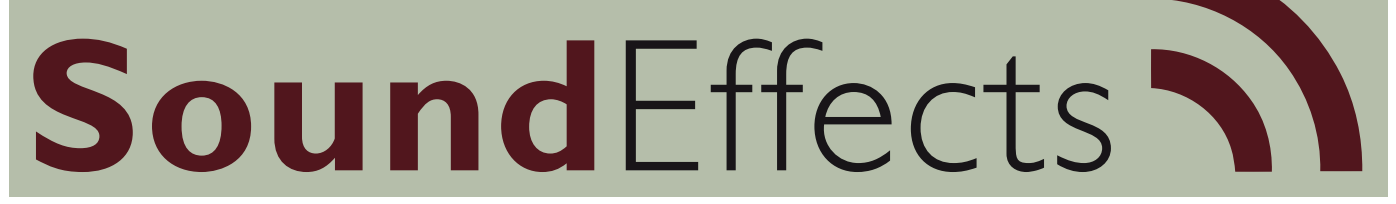

An Interdisciplinary Journal of Sound and Sound Experience

\title{
Jordan Lacey
}

\section{Conceptual overlays for urban soundscape design emerging from a transversal analysis of Lefebvre, Deleuze and Guattari, and Arendt}

\author{
Jordan Lacey \\ Sound-artist, musician, soundscape designer and \\ sessional lecturer in Melbourne, Australia \\ jordan.lacey@rmit.edu.au
}




\begin{abstract}
This paper describes theoretical developments that have emerged alongside the author's urban soundscape design practice. The theory, which emerged from a transversal analysis of Henri Lefebvre, Gilles Deleuze and Felix Guattari, and Hannah Arendt, particularly their philosophical investigations of space, rhythm and nature, is presented as four conceptual overlays to aid soundscape design practices in urban spaces. The first conceptual overlay, Radiating Striations of Centralities, synthesises spatial discussions of Deleuze and Guattari and Lefebvre into soundscape design approaches that simultaneously respond to centralized controls and the peripheries of urban spaces. The second conceptual overlay, The Isorhythimc Refrain, convolves Deleuze and Guattari's refrain and Lefebvre's isorhythms into identifiable socially controlling rhythms that unfold as captured sonic and gestural forms throughout urban spaces. The third conceptual overlay, Altered Soundscapes as Emergent Ecologies, investigates Guattari's a-signifying rupture and the potential of soundscape design as rupture to affect the emergence of Lefebvre's new nature(s) in urban spaces. The fourth conceptual overlay, Disassembling the Collective Assemblage of Enunciation, discusses Arendt's reflections on social rhythms subsuming society into automated behaviour, and the challenges that can be presented to such automated behaviour through the act of soundscape design. The four conceptual overlays provide sociopolitical and ecological understandings of the urban that contribute to a soundscape design practice from which public soundscape installations are created to subvert controlling spatiotemporal rhythms of the urban for the emergence of new nature(s). The article concludes by suggesting that due to the amorphous characteristics of sound the soundscape designer is in a unique position to affect immediate sociopolitical and experiential transformations of urban spaces.
\end{abstract}

\title{
The emergence of soundscape design
}

The concept and practice of urban soundscape design emerged in twentieth-century art and philosophy through radical approaches to composition. The futurist Luigi Russolo, in his manifesto The Art of Noises, describes 'noise-sound' (Russolo, 1913, p. 5), which considers natural and industrial sounds as comparable compositional components. John Cage's 4'33" redirects the listener's attention from musical constructions to existing sounds, thereby encouraging perceptions of soundscape as composition. Pierre Schaeffer's sound object affords phenomenological perceptions of sounds, which broadened the imaginative potential for relationships with sonic milieux. R. Murray Schafer, who introduced the term soundscape and founded the World Soundscape Project (WSP), describes 'the soundscape of the world as a huge musical composition unfolding around us ceaselessly' (Schaffer, 1977, p. 205). ${ }^{1}$ The sonic research institute CRESSON, under the leadership of Ayogard, developed 
the structural notion of sound effect ${ }^{2}$ from which the metaphor of city as musical instrument inspires 'analysis in relation to performance, the ways to play and conduct sounds, the design and use of effects' (Ayogard \& Torgue, 2005, p. 4). Max Neuhaus was the first to produce publically installed electroacoustic soundscape compositions (most famously Times Square) which recontextualises 'composition as the orchestration of environmental conditions' (LaBelle, 2006, p. 156). Most recently, Steve Goodman (2010) introduced the concept of the 'ecology of fear' - internal subjective emotions that respond to low-frequency urban sounds with a permanent sense of anxiety and unease - which is met by artistic responses to the city as instrumentarium, including the emergence of sonic war machines and vibrational architecture (pp. 73-77).

\section{Philosophy as praxis}

The comparative analysis has emerged from a soundscape design and sonic philosophy practice (see Lacey \& Harvey, 2011a; Lacey \& Harvey, 2011b; Lacey, 2012a; Lacey, 2012b, Lacey, 2014), which has been shaped by Deleuze, Lefebvre and Arendt's comments on philosophy as praxis. Deleuze states that:

\section{A theory is exactly like a box of tools [...] It must be useful. It must function. And not for itself. If no one uses it, beginning with the theoretician himself [...] then the theory is worthless (Foucault, 1977, p. 208).}

Lefebvre states that 'thought strengthens itself only if it enters into practice: into use' (Lefebvre's emphasis) (Lefebvre, 2004, p. 69). And Arendt suggests that the 'most important category of human activity [...] is action, or praxis' (Fry, 2009, p. 44). The conceptual overlays inform an urban soundscape design practice that has been shaped by Lefebvre, Deleuze and Guattari, ${ }^{3}$ and Arendt's philosophical investigations of nature, space and rhythm, which in conjunction with the creation of public soundscape installations are considered praxis that attempts to affect change within the sonic flows and rhythms of urban spaces.

\section{Contextualising the practice}

The soundscape design methodology practiced by the author 'repatterns' the sonic and social components of the soundscape for the realisation of potential listening experiences, and the deprogramming of space for the emergence of creative interactions amongst urban dwellers. Repatterning the urban soundscape is a term invented by the author, which seeks a methodology that encompasses the aesthetic approach of the WSP and the structural approach of CRESSON (Lacey, 2013, p. 125). For example, Schafer's romantic maxim, 'the basis of all soundscape design ought 
to be to develop the artful patterning of what is already there' (Schafer, 1993, p. 103), and CRESSON's sound effect, which deconstructs soundscapes into multiple perceptual effects, convolve in the term 'repatterning'. Soundscape designs, created by the author, which have applied the repatterning technique, include shutdowns ${ }^{4}$ of existing sound sources, electroacoustic sound interventions ${ }^{5}$ and pedagogical approaches to soundscape immersion. ${ }^{6}$ However, this paper's focus is on the conceptual overlays that emerged from a transversal analysis of Lefebvre, Deleuze and Guattari, and Arendt, which was completed in conjunction with the author's soundscape design practice. A soundscape designer ${ }^{7}$ can apply the conceptual overlays to produce sociopolitical understandings of the urban, which can inform the practitioner's approach to the design of public soundscape installations.

\section{Definition of terms utilised by the conceptual overlays}

Attempting to define the concepts of the discussed philosophers, particularly Deleuze and Guattari, is challenging. ${ }^{8}$ The density and abstractness of the language defies reduction to definitive statements. As such, not all readers will agree with the author's definition of concepts, or use of terms. In particular, the definitions are restricted within the context of human experience, whereas (particularly) Deleuze and Guattari's ideas are not human centred. ${ }^{9}$ The reader should consider that the definitions have been shaped in specific relation to the intent of a soundscape design practice, which, as praxis, attempts to transform sociopolitical controls inherent to urban space to afford diverse experiences for urban dwellers. ${ }^{10}$

\section{Actual and virtual (potential) realties in space}

Space that is accessible to the senses can be described as actualised realities. But also existing in space are virtual realities. Virtual realities are potential realities that have not manifested in space. As such, the virtual exists, but is not actualised. A practical example is the city worker who walks the same route more or less the same way, every day, to work. The gestures, sounds and chosen route of the city worker are an observable and audible actualised reality of the city worker's presence. But inherent in the daily acts of the city worker are the virtual realties of alternative gestures, sounds and routes that have not been actualised.

\section{Territorialisation, deterritorialisation and reterritorialisation}

Deleuze and Guattari use birdsong to describe these terms in their chapter 'On the Refrain' (Deleuze and Guattari, 2004, pp. 356-358). When a bird sings, it territorialises space. The audible locus of its song becomes a territory which the bird claims. When the bird stops singing the space is deterritorialised and becomes an open space for the songs of other birds to territorialise. When the bird starts singing again it may 
territorialise the space with the same song, or it may reterritorialise the space with a new song. For example, rather than a song that excludes others of the same species, the song may be one that attempts to attract a mate. The important point here is that the refrains of birdsongs are constantly reshaping a space into multiple experiences and power relations. A comparative urban example is a ventilation outlet that emits the sound of rushing air. Its 'song' does not change from day to day; and thus, the ventilation outlet territorialises space on an everyday basis.

\section{Subjectivities}

A subjectivity is considered a creative expression or response that emerges as experience within the city dweller. Multiple subjectivities (many creative expressions or responses) can emerge simultaneously within a single person or a group of people. For example, a city dweller may encounter a sound installation and be simultaneously surprised by its sudden appearance, curious about its purpose and manifest thoughts, gestures and actions relating to this - this is referred to as the emergence of subjectivities. Additionally, there may be others in the space also having multiple experiences; in this scenario there are multiplicities of subjectivities. A captured subjectivity is a subjectivity that occurs as a repetitive expression or response on an everyday basis. Large groups (such as societies) of people who express the same subjectivity are considered to be captured by the collective assemblage of enunciation (see below). The emergence of subjectivities can also be referred to as the actualisation of potential realities.

\section{The collective assemblage of enunciation}

An enunciation can be considered a spoken word or perhaps a gesture or thought (expressions). An assemblage, loosely speaking, is considered a collection of parts. The parts within collective assemblages of enunciation in urban settings are considered the subjective expressions of people. Therefore, a collective assemblage of enunciation is considered the thoughts, ideas and gestures that are collectively expressed by a group of people. In this paper a collective assemblage of enunciation can be considered a subjectivity (an expression) that has captured a large number of people. Entire cities and nations can be thought of as being caught within a collective assemblage of enunciation; for example, the mass media can inform a collective assemblage of enunciation in which the thinking of whole populations is defined by the manner in which news items are reported in media outlets. ${ }^{11}$ Likewise, the response of people to an emergency siren can be considered a collective assemblage of enunciation (which suggests its positive attributes) as is evidenced by the similarity of gestures within a siren's sonic range. The dominance of a collective assemblage of enunciation is challenged by the emergence of multiplicities of sub- 
jectivities, which can fracture a collective assemblage of enunciation into multiple creative expressions.

\section{The a-signifying rupture}

A city can be considered a system of signs that represses the potential of subjective emergences; everywhere, spatial controls are signified - commodity fetishisation, power relations, social obligations - and as such the experience of the city dweller (the expressed subjectivities) can be said to be determined by the system of signs. An a-signifying rupture occurs when the signs that inform a space momentarily disappear. Within this space there is a vacuum of perception, which subjectivities instantaneously fill. As such, an a-signifying rupture can be defined as an absence of signifiers from which subjectivities emerge. Public soundscape installations create a-signifying ruptures by subverting the systems of signs that are signified by site-specific sounds.

\section{Second (new) nature}

Nature is a complex and possibly indefinable term. ${ }^{12}$ However, Lefebvre uses the term as an effective way to differentiate spaces. In nature spaces systems of signs are absent, thus honest, unmediated experiences can occur. The urban (or social) space, on the other hand, is duplicitous (Lefebvre, 1991, p. 81); the system of signs allows the city to present itself as something other than it is experienced. For example, the advertising billboards of the city promise a life of comfort and ease, while in reality the city dweller must contest with spaces defined by power relations. New natures within urban spaces are considered codeless, honest and creative spaces in which multiple subjectivities can emerge due to the absence of spatiotemporal controls.

\section{Lines of flight}

If urban space is considered captive to spatiotemporal controls that determine the experience of city dwellers, a line of flight can be considered an escape route towards alternative lived experiences. A public soundscape installation that offers alternative sonic experiences can be considered a line of flight in which subjectivities (creative expressions and responses) emerge that provide the city dweller with new experiences. From a line of flight the 'urban nomad' emerges. The nomad (understood by Deleuze and Guattari as an inhabitant of smooth space) is a creative city dweller whose experiences, paths and actions are the manifestation of unique subjectivities, which operate beyond the spatiotemporal controls and bureaucratic functionalisms of the city. A primary concern of the conceptual overlays is to create the conditions for the emergence of the urban nomad. 


\section{Overview of comparative analysis}

The conceptual overlays for urban soundscape design have emerged through a comparative analysis of the four philosophers, Lefebvre, Deleuze, Guattar ${ }^{13}$ and Arendt. Comparative concepts explored in this paper include: from Deleuze and Guattari, 'striated and smooth space', and 'the refrain', which are compared to, in sequential order, Lefebvre's the 'production of space' and 'rhythmanalysis'. The comparative analysis of these concepts produces perspectives for creative approaches to deterritorialising urban space, particularly in regard to urban spaces' domination by bureaucratic functionalism. These emergent perspectives are explored through proposed consistencies between Guattari's 'ecosophy' and Lefebvre's 'second (or new) nature' in regard to public art, nature and social relations. Arendt's reflections on rhythm and nature merge with the previous discussions of social space, rhythm and nature to propose an explanation for society's surrender to the collective assemblage of enunciation, and the role of soundscape design in providing lines of flight from such controls.

\section{Conceptual overlay I: Radiating Striations of Centralities}

Lefebvre's understanding of space as fragmented according to a rational order is conceptually synonymous with Deleuze and Guattari's striated space, which conceives of space as carved, divided and bound. In The Production of Space, Lefebvre's states:
A classical rationality [...] appears to underpin various spatial distinctions and divi- sions. Zoning, for example, which is responsible - precisely - for fragmentation, break-up and separation under the umbrella of a bureaucratically decreed unity [...] What is being covered up here is a moral and political order: the specific power that organises these conditions, with its specific socio-economic allegiance, seems to flow directly from the Logos - that is, from a 'consensual' embrace of the rational (Lefeb- vre, 1991, p. 317).

Understanding space as representational of a rational order imposing controls on lived experience exposes challenges to creative design intervention in the city, while simultaneously illuminating lines of flight from these controls via bureaucratic cooperation and/or subversive methods. ${ }^{14}$ For the creative practitioner, cooperative methods consider the controls on space that emanate from central bureaucracies, while subversive methods challenge the striated, as if peripheral striated spaces were disembodied from their central genesis. A comparative example is government-funded art projects, in which the designer acknowledges the centrality of control, and illegally applied street art, in which centrality is ignored in favour of the conditions of the peripheral. 
Lefebvre further elaborates the effects of dominated space on human experiences:

As a body of constraints, stipulations and rules to be followed, social space acquires a normative and repressive efficacy [...] that makes the efficacy of mere ideologies and representations pale in comparison (Lefebvre, 1991, p. 358).

Thus, bureaucratic power dominates urban space by informing the social space of cities, a dominating power that only becomes apparent when action that contradicts the bureaucratic programming of space is present. This has been experienced in the author's soundscape design practice in regard to a soundscape intervention that temporarily deterritorialised space through the shutdown of a dominant industrial sound source, for the reterritorialisation of space with a human-centred milieu. It is an example of challenging the rational order via bureaucratic cooperation:

Over a period of three months the following departments had to be contended with on a weekly and sometimes daily basis: health \& safety officers, fire services, facility services, property services, audio-technical manager, ethics committee, the student union, market stall holders, and client-relations managers. Additionally cleaners complained on the day that their route to near-by rubbish bins were being blocked, security kept a presence, and occasional passers-by surveyed the area and made concerned phone-calls [...] demonstrat(ing) challenges to creative responses to soundscape design in the city (Lacey, 2012b, p. 16).

And all this for two separate interventions, one lasting for half an hour and the other for three hours (see Lacey, 2012b for more details).

Deleuze and Guattari introduce their concept of striated and smooth space in two chapters, 'Treatise on Nomadology - the War Machine', and 'The Smooth and the Striated'. Striated space can be considered the built environment: our towns, cities and agriculture, explained as 'parallel verticals (that) have formed an independent dimension capable of spreading everywhere' (Deleuze and Guattari, 1997, p. 408); smooth space can be considered the space of the nomads, of deserts and steppes (or to generalise, the natural), whose relationship to space is vortical (where any point of space can be occupied in any point of time). The creative practitioner acts to reimpart smooth space within striated space by deterritorialising bureaucratic controls of urban milieux for the emergence of creative experiences - the boundless condition of the nomad. It should be noted here that the experience of the nomad is more expansive than being afforded multiple paths in smooth space; the nomadic experience is informed by diverse subjectivities as related to imaginative relationships with the immediate environment. Architectural approaches that favour the creation of open spaces and more transparent modular designs create smooth spaces in the sense of affording diverse flows; however, this does not necessarily lead to diverse expressions of subjectivities. Spatiotemporal controls, having 
a central genesis, can still exert influence on everyday lived experiences, even when peripheral designs attempt to subvert those controls.

The discussion of striated and smooth is not dualistic; striated and smooth spaces are characteristics of space in constant interaction, which cause a multiplicity of becomings:

We must remind ourselves that the two spaces in fact exist only in mixture: smooth space is constantly being translated, transversed into a striated space; striated space is constantly being reversed, returned to a smooth space (Deleuze and Guattari, 1997, p. 524).

The argument that there is a continuously active mixture of striated and smooth spaces can, from a design perspective, be understood as identifying the smooth (spaces where the virtual can manifest) within the striated (controlled spaces), thus identifying lines of flight, that is, the potential emergence of subjectivities within the peripherally located nomad. This is an affective design response to urban space; however, focusing on the peripheries risks becoming a fantasist's notion, as it is clearly bureaucracies, by continuously affecting striations in global space,,$^{15}$ that are in the ascendant. Accordingly, the soundscape designer responds to the demands of centralised controls while maintaining a creative focus on the periphery as the site for creative emergences.

Lefebvre was critical of thinking that focused exclusively on the periphery, emphasising instead the importance of recognising the power of centralised bureaucracies to impose controls on (social) space. Stuart Elden quotes Lefebvre as:

Suggesting that [the then] contemporary concentration on marginal/peripheral groups 'neglects the centres and centrality; in a word the global. These are pin-prick operations, suggesting that we should 'enjoy ourselves! Don't work! We are all delinquents, sexually obsessed, schizophrenics.' By this it is clear he has Deleuze and Guattari in his sights (Elden, 2004, p. 240).

The benefit for creative design intervention in conceptualising striated space as emanating from centralities is that it provides a focus for action, that is, identifies controlling agents against which to struggle. All urban striations have a source that if recognised can assist the soundscape designer (practically and imaginatively) in the formation of soundscape installations. If Deleuze and Guattari's premise of the smooth has been determined to provide lines of escape for the peripheral nomad only, rather than affecting broader societal change, then Lefebvre's criticism that Deleuze and Guattari ignore centralities by focusing on the periphery seems justified. A combination of these approaches by the creative practitioner aims to transform striations that radiate from centralised controls by simultaneously creatively 
responding to peripheral striations while seeking complementary approaches with the genesis of these striations.

Lefebvre's concept of fragmented space, controlled by a rational order, provides a context for understanding how striations emerge from centralised bureaucracies; and Deleuze and Guattari's description of the reimparting of smooth space provides a context for the reterritorialisation of space through creative design intervention. Striated space can be considered the production of space in regard to the domination of space by bureaucracies, where space is carved and sectioned for functionalism, while the reimparting of smooth space can be understood as the continuous attempt by the creative practitioner (and/or the urban nomad) to reterriroialise urban space for the diversification of human experience. While bureaucratic controls of space are expressed through its fracturing and striating of space, the power of the creative act is its capacity to reimpart smooth space, thus affecting a mixture of sensual and imaginative relationships with the city (smooth) and the controlling functionalisms of space (striated). The role of soundscape design is unique in this tension; it is difficult to materially reimpart the smooth in spaces dominated by concrete and steel, but sound is fluid, flowing and amorphous; the field of sounds, and its effects, can emerge and recede in an instant.

\section{Conceptual overlay II: The Isorhythmic Refrain}

Deleuze and Guattari's chapter 'On the Refrain' explores the territorialisation of space through repetitive, particularly sonic, motifs. ${ }^{16}$ They make use of many musical terms including refrains, motifs, counterpoints and rhythms. Likewise, Lefebvre's Rhythmanalysis, which analyses space through the rhythms that inform social organisation, also utilises the language of music for his descriptions. Thus, music, and more generally the sonorous, is significant to the Refrain's and Rhythmanalysis' descriptions of time. Time, like music, is perceived as polyphonous, capable of shifting its tempo, dynamics and character.

Deleuze and Guattari contend that the sonorous holds a unique place in the refrain. They state:

The refrain remains a formula evoking a character of landscape. The refrain has two poles. These poles hinge not only on an intrinsic quality but also on a state of force on the part of the listener (Deleuze and Guattari, 1997, p. 385).

The link between character of landscape and listening is significant for soundscape design approaches. The refrain exists autonomously in a space while simultaneously evoking experiences that territorialise or deterritorialise space as related to the immanent lived experience of the listener. A repetitive refrain that exists unimpeded, becoming embedded in the everyday, has the effect of territorialising space 
and causing repressive listening experiences (for example, the day-to-day drone of air conditioners, or muzak piped into consumer spaces). However, refrains can also diversify space by activating both poles of listening with the continuous process of deterritorialisation and reterritorialisation. As such, the refrain allows soundscape designers to recognise and challenge spaces dominated by repetitive sonic refrains by responding with counter-refrains that affect creative listening responses.

In Rhythmanalysis Lefebvre describes time as a mixture of the cyclical and the linear repetitive, where cyclical and linear rhythms operate in comparable ways to striated and smooth space: 'cyclical repetition and the linear repetitive separate out under analysis, but in reality interfere with one another constantly' (Lefebvre, 2004, p. 8). Considered in this way smooth space, like cyclical time, refers to the open, the 'natural'; and striated space, like linear time refers to the repetitive patterns of functional spaces. In the convolution of Lefebvre's and Deleuze and Guattari's temporal conceptualisations the refrain can be understood as having either a natural cyclical or linear repetitive quality, where natural cyclical refrains are common to nature space and linear repetitive refrains are common to urban space. For example, Deleuze and Guattari discuss the capacity of the refrains of birdsong (as discussed above) to instantly and unpredictably territorialise, deterritorialise and reterritorialise space. In contrast, the refrains of urban spaces are informed by technologies that dominate space through linear repetition (for example ventilation outlets, sirens, muzak and pedestrian crossing signals).

Lefebvre dedicates a chapter in his Rhythmanalysis to dressage, which explores the relations of rhythm and gesture. ${ }^{17}$ In the chapter Lefebvre describes the effects of space on people's gestures, which are informed by a military model:

Societies marked by the military model preserve and extend this rhythm through all phases of our temporality: repetition pushed to the point of automatism and the memorization of gestures (Lefebvre, 2004, p. 40).

Here we find cyclical and linear rhythms in mixture, where the linear repetitive gestures of city workers and consumers (gait, footsteps and transport routes) are contained within the cyclical rhythms of social organisation (as organised along the Earth's cyclical day/night axis). This convolution of gestural and sonic expressions in the human rhythms of social organisation exists alongside the linear-repetitive rhythms of technologies. The ubiquity of the linear-repetitive refrain in both human activity and technological functions is suggestive of an abstract quality that unfolds throughout urban space, and as such can be considered a controlling presence in space (which, as will be explained, is known as the isorhythmic refrain). Here the refrain becomes synonymous with an oppressive landscape. As Deleuze and Guattari explain, '[the refrain] also effects the most massive of reterritorializations, the most numbing, the most redundant' (Deleuze and Guattari, 1997, p. 383). 
A rhythmanalysis is concerned with detecting the presence of space, which informs the present (immediate experience): " $[T]$ he act of rhythmanalysis, transforms everything into presences, including the present, grasped and perceived as such' (Lefebvre, 2004, p. 23). The present is immediate lived experience, but presence is what a rhythmanalysis will uncover: the affective forces in space. Lefebvre distinguishes several types of rhythm as presences informing space. Of interest to the soundscape designer is eurhythmia, arrhythmia and isorhythmia. 'Eurhythmia (that of a living body, normal and healthy) presupposes the association of different rhythms). In arrhythmia, rhythms break apart, alter and bypass synchronization' (Lefebvre, 2004, p. 67). Perhaps in this comment Lefebvre is proposing a therapeutic model for space where identified arrhythmias might be reconfigured as eurhythmias. The closest he comes to suggesting this is: 'intervention through rhythm [...] has a goal, an objective: to strengthen or re-establish eurhythmia' (Lefebvre, 1991, p. 68). In his preferencing of eurhythmias Lefebvre seems to be suggesting the establishment of a harmony of rhythms; ${ }^{18}$ however, arrhythmia may be a desirable alternative to eurhythmia when the soundscape designer is confronting isorhythmias. Lefebvre attaches no obvious qualities to isorhythmia, describing it simply as 'the equality of rhythms' (Lefebvre, 2004, p. 67), which are comparable to a conductor who ensures an orchestra is equally synchronised to the same rhythm. In this paper the presence of isorhythmias are considered controlling refrains that have repetitive qualities that unfold throughout urban space as the linear repetitive, sonically manifesting in the gestures of workers, consumers and the operations of technology. In response, creative soundscape design seeks the deterritorialisation of the isorhythmic refrain by reterritorialising space with eurhythmic ${ }^{19}$ and arrhythmic ${ }^{20}$ soundscape installations.

The refrain can be considered as cyclical or linear. Isorhythmic refrains tend towards the linear repetitive in that the isorhythmic refrain controls (territorialises) space through repetition. An example of this is the Muzak Corporation, ${ }^{21}$ which actively territorialises space with sonorous linear repetitive rhythms that encode space for consumerism and industriousness. Soundscape installations that manifest sonic eurhythmias and/or arrhythmias are able to create (territorialise) or repattern (reterritorialise) refrains within the urban soundscape, ${ }^{22}$ which challenges the homogenising impact of the isorhythmic refrain.

\section{Conceptual overlay III: Altered Soundscapes as Emergent Ecologies}

Transversing spatiotemporal explorations of Deleuze and Guattari, and Lefebvre is the realisation of the potential for lived experiences in cities that escape the functional and the banal; however, lived experiences remain subordinate to spatiotem- 
poral controls and the collective assemblage of enunciation until creative praxis actualizes this potential. As Guattari explains:

At the heart of all ecological praxes there is an a-signifying rupture, in which the catalysts of existential change are close at hand, but lack expressive support from the assemblage of enunciation (Guattari, 2008, p. 30).

Guattari's argument can be understood as identifying lines of flight from the controls of functional space that is similar in effect to Lefebvre's considerations of the creative transformation of urban space into new natures. Lefebvre and Guattari's discussions of nature, analysed comparatively, suggest the potential of soundscape installations to act as a-signifying ruptures for the creation of new natures.

Lefebvre is the ignored ecological philosopher according to Stanley Aronowitz, who describes Lefebvre as:

The ecophilosopher of the 21st century, for he made the connection between the massive despoiling of the global ecosystems, the new shape of social time and social space and the struggle for the transformation of everyday life which, he claims, is the key to the project of changing life and repairing our collective relationship to nature (Aronowitz, 2007, p. 133).

Aronowitz's description of Lefebvre's ecophilosophical approaches resonates with certain ecological writings of Guattari. Guattari's The Three Ecologies departs from traditional environmentalist dialogue of a separation between nature and culture replacing it with 'an ethico-political articulation - ecosophy - between the three ecological registers (the environment, social relations and human subjectivity)' (Guattari, 2008, p. 19). The similarity between Lefebvre's and Guattari's approaches to ecology is that both realised environmental concerns are inextricable from social concerns and the necessary subjectification of the everyday. ${ }^{23}$

Lefebvre depicts natural space as honest space: 'Nature presents itself as it is, now cruel, now generous. It does not seek to deceive; it may reserve many an unpleasant surprise for us, but it never lies' (Lefebvre, 1991, p. 81). However, the potential for unmediated subjective experiences with nature is increasingly disabled, as lived experiences in natural areas become controlled by machinic assemblages (park rangers, tourist centres, signage) and collective assemblages of enunciation (rules and regulations, feelings of reification and guilt), which turn nature into a patchwork of state-sanctioned theme parks. Alternatively, wilderness (defined here as codeless spaces outside of spatiotemporal controls), or what remains, holds the last genuine experiences of nature, as understood by Lefebvre. ${ }^{24}$ As our relationship with the wildness of nature disappears concomitant with the ever-increasing production of urban spaces, the need to recreate our urban spaces with the effects of nature (in regard to lived experiences) becomes paramount. 
Lefebvre's conception of second (or new) nature is explained in the following passage in which he:

'Calls for the immediate production or creation of something other than nature: a second, different or new nature, so to speak. This means the production of space, urban space, both as a product and as a work, in the sense in which art created works. If this project fails, the failure will be total, and the consequences of that are impossible to foresee' (Lefebvre, 1991, p. 109; emphasis added).

The emergence of new natures within urban spaces is achieved by the creation of works - in the sense that art creates works - which challenge the spatiotemporal controls of the urban. This position is given further context by Jon C. Tinnel's (2012) explanation of Guattari's ecosophy:

For Guattari, ethico-aesthetic paradigms do not necessarily deal with art as we traditionally conceive it, but seek to incorporate an aesthetic order - an artist's 'way of assuming their existence' - into the existential territories of everyday life, within and beyond the studio or the museum (Tinnel, 2012, p. 362).

An artist's way of assuming his or her existence is, presumably, impossible to define; however, for the purposes of this paper it is characterised as the spontaneous emergence of diverse subjectivities (both as innate sense and created works). If everyday life was to assume this characterisation of the artist's existence, then urban space would have the quality of perpetually manifesting (actualising) virtual realities into the everyday. In everyday urban spaces virtual realities are always in abundance, but are unable to emerge within the city's spatiotemporal controls. Art in public spaces, by actualising the virtual through the creation of a-signifying ruptures, is able to realise the emergence of new natures within urban spaces. There is the danger of reading implicit statements here that nature is an artist that the everyday, through human intervention, should attempt to impersonate, but of course such anthropomorphisms of space could not be ascribed to either philosopher. Rather, the artist can seek the emergence of subjectivities along the lines of Guattari's ecosophical approach, which is described by Tinnel as the 'processual disjunction of discrete elements [...] continually broken down into partial objects along a plane of immanence on which they engage and re-engage in infinite productive syntheses with other partial objects' (2012, p. 381). To contextualise this quote within the discussed soundscape design practice: the partial objects (considered here as the minimal units of sound - both structurally and perceptually) of the urban soundscape are disassociated and set in motion causing continuously creative reengagements between the partial objects that were previously set into repetitive patterns based on the spatiotemporal controls of the city. Soundscape designs repattern partial objects by resynthesising existent sounds (with the aid of sound- 
scape installations) and actualising the virtual (which occurs through the ongoing resynthesis of sounds to manifest new sounds), while concomitantly subverting the capturing of the everyday away from set forms and patterns (as determined by the bureaucratic striating of space and the isorhythmic refrain). This prevents collective assemblages of enunciation (captured subjectivities) from repressing potential emergences of new subjectivities (newly created sounds and listener experiences of those sounds). Such acts of the urban artist imply the power implicit in nature's diverse milieux, which contains the capacity for limitless subjective emergences.

To consider nature and its relationships to emergent subjectivities, we need only consider the simplest of moments. When walking through bush land a sudden gust of wind shakes the trees overhead, just as the footstep crunches into dry leaves, and a distant bird sings its refrain; for reasons irrational, a sense of significance, of beyond-the-ordinary is experienced by the listener. The experience of the listener is momentarily free from all collective assemblages of enunciation and spatiotemporal controls. The challenge for creative praxis is to release the potential of such experiences in urban spaces: to create the moment when all controls evaporate and the urban nomad's listening experience expands outwards towards the horizons of the city, escaping the spatiotemporal controls of space to which human society is bound. Urban sounds, as amorphous materials replete with immanent potential, can be quickly transformed by the soundscape designer into a-signifying ruptures to affect the emergence of new natures and thus, multiplicities of experiences.

\section{Conceptual overlay IV:}

\section{Disassembling the Collective Assemblage of Enunciation}

In Hannah Arendt's book The Human Condition the activities of human life are categorised as labour, work or action. According to Arendt, action, especially political action (which Arendt calls the 'vita activa'), is the most important expression of the active human life. However, it is Arendt's discussions of labour as the dominant force in contemporary life that are of interest here. Arendt's reflections on rhythm and nature, particularly in relation to the actions of 'homo laborans' (Arendt's term for labourers), are effective in clarifying certain ideas of Deleuze and Guattari, and Lefebvre - in particular, the willingness of societies to submit to collective assemblages of enunciation. Like Deleuze and Guattari, and Lefebvre, Arendt is suggestive of an escape route from the controls of functionalised urban space, and collective assemblages of enunciation, through the creation of art in public spaces.

Arendt understands rhythm as the cycles of nature (daily, seasonal) where the labouring process emerges as a rhythm synchronous with the cycles of nature. 'Homo laborans' (man [sic] as labourer) metabolise nature without leaving anything lasting 
in the built world, which is the role of 'homo fabricus' (man [sic] as creator). According to Arendt, 'homo laborans' are content to be immersed in the rhythms of nature:

The 'blessing or the joy' of labour is the human way to experience the sheer bliss of being alive which we share with all living creatures, and it is even the only way men, too, can remain and swing contentedly in nature's prescribed cycle, toiling and resting, labouring and consuming, with the same happy and purposeless regularity with which day and night and life and death follow each other (Arendt, 1958, p. 106; emphasis added).

It is this 'blessing or joy', as Arendt puts it, that has become so dangerous for the human society (and the built world) which was created by 'homo fabricus' and has been overtaken by 'homo laborans' (in the present sense - city workers and consumers) who treat society (or the built world) as if it was still the original form of nature, producing and consuming, vis-a-vis metabolising nature, with a destructive force. The process appears natural to the contemporary society of 'homo laborans', who propelled by the collective assemblage of enunciation are able to conceptually normalise the destructive cycle of production and consumption. Arendt wrote the following prescient passage in the 1950s:

\section{The danger of future automation is (that) all human productivity would be sucked into an enormously intensified life process and would follow automatically, without pain or effort, its ever-recurrent natural cycle. The rhythm of machines would mag- nify and intensify the natural rhythm of life enormously, but it would not change, only make more deadly, life's chief character with respect to the world, which is to wear down durability (Arendt, 1958, p. 132).}

Arendt's description resonates with the earlier discussion of the isorhythmic refrain. The appropriation of natural cycles into cycles of production and consumption by contemporary 'homo laborans' suggests that the natural cyclical is absorbed into the linear-repetitive modes of the everyday in increasingly efficient (and destructive) ways. The collective assemblage of enunciation that has emerged from this rhythmic process reinforces the 'naturalness' of contemporary life, because its rhythms of production and consumption are appropriations of natural rhythms. This is the isorhythmic refrain masquerading as the rhythms of the natural cyclical.

These isorhythmias, which inform the collective assemblage of enunciation, have a homogenising effect on the urban. Challenging this urban condition is integral to the intent of the conceptual overlays, which, similar to Guattari's The Three Ecologies, hope to 'counter the pervasive atmosphere of dullness and passivity' (Guattari, 2008 , p. 45) of the everyday. It is the repetition of the isorhythmic refrain which homogenises space, ensuring that potential subjectivities that are actualised in the smooth spaces of the natural remain as virtual (and thus unrealized) experiences 
in the striated spaces of the urban. This concern echoes Arendt's prediction, now written over 50 years ago:

\begin{abstract}
The last stage of the labouring society, the society of jobholders, demands of its members a sheer automatic functioning, as though individual life had actually been submerged in the over-all life process of the species and the only active decision still required of the individual were to let go, so to speak, to abandon his individuality, the still individually sensed pain and trouble of living, and acquiesce in a dazed, tranquilised, functional type of behavior (Arendt, 1958, p. 322; emphasis added).
\end{abstract}

Arendt's description of a society subsumed by the isorhythms of production and consumption seems one destined for self-destruction, a cautionary philosophy also suggested by Deleuze and Guattari, and Lefebvre in their explanations of the domination of space and time by the controls of functionalism. Arendt's ideas suggest why the contemporary collective of enunciation, which is expressed by homo laborans, is so seductive: because it seems natural; and yet, it is anything but 'natural'. Rather, it is inherently destructive (in the Arendtian sense of 'wearing down durability').

The intention of the fourth conceptual overlay is to compel the soundscape designer (or any creative practitioner) to disassemble the collective assemblage of enunciation by challenging the illusionary sense of nature (that is, the isorhythmic refrain masquerading as the natural cyclical), which has normalised the destructive tendencies of contemporary society. Spaces dominated by the isorhythmic refrain are spaces in which the destructive processes of 'homo laborans' have manifested. In response the soundscape designer creates soundscape installations that desynchronize the isorhythmic refrain. Muzak, air conditioning and traffic sounds can be described as sonic manifestations of the isorhythmic refrain, which contribute to the collective assemblage of enunciation of 'homo laborans'. By reterritorialising urban space with refrains that challenge isorhythmic refrains, a-signifying ruptures may emerge that create new natures, in which diverse human experiences can occur. It is the experience of these new natures that may serve to challenge the illusionary sense of nature, and thus the collective assemblage of enunciation that has normalised the destructive processes of contemporary societies.

All thinkers discuss the potential of art and the artist to disassemble the destructive capacity of the collective assemblages of enunciation. Lefebvre calls for the creation of works in urban space, like art creates works. Guattari asks for the everyday to assume the existence of an artist. And Arendt suggests that the artist [...] strictly speaking, is the only "worker" [creators of the built world] left in a labouring society' (Arendt, 1958, p. 127). The soundscape designer is able to recognise and reterritorialise and deterritorialise the rhythms of the urban, that is, presences that inform the everyday, by countering the destructive repetitiveness of the isorhythmic refrain. The emergence of new natures can challenge the collective 
assemblage of enunciation by rupturing the spatiotemporal controls of the urban, which are responsible for the normalisation of the destructive capacity of contemporary urban life.

\section{Applying the four conceptual overlays to an urban soundscape design practice}

The conceptual overlays discussed in this paper, when applied by the soundscape designer, render sociopolitical understandings of the contemporary city from which soundscape design responses can be realised. The overlays frame everyday experience as captured (predictable and repeated) forms that can be identified and then diversified through the creation of soundscape installations. The conceptual overlays are not proposed as a definitive statement on urban milieux. Rather, they provide a specific sociopolitical perspective from which a soundscape designer may choose to realise his or her works. Furthermore, this paper is not suggesting that all urban spaces can be defined as capturing human experiences into set forms and patterns. For example, contemporary approaches to the design of space create smooth spaces that afford a diversity of transitory routes and alternative social conditions for the urban dweller. However, reimparting the smooth within the striations of the city does not necessarily suggest a-signifying ruptures in which creativity emerges; smooth spaces in contemporary cities may suggest an ideal of openness and diversity, while continuing to signify the controls of centralised bureaucracies (for example, smooth space makes state observation of human activity easier).

Recent efforts by the European Union and the World Health Organisation to create an awareness of the need for healthier soundscapes (for further discussion, see Hellstrom, 2012, pp. 1-2) may be characterised in similar ways. The reimparting of the smooth (open, less distracting, typically 'natural' sounds) within the striated (particularly traffic and machine sounds) is promoted for the realisation of the healthier citizen. But this is not an argument for creative emergences in the everyday, but rather, the reshaping of human experience according to centralised definitions of what is or is not considered healthy. Alternatively, the specific focus of this paper is rupturing existing spatiotemporal controls through the creation of soundscape installations for the emergence of subjectivities, where a subjectivity is an undefined creative expression or response by the listener, independent of bureaucratic decrees and centralised controls. The conceptual overlays presented in this paper inform a soundscape design practice that seeks ruptures in space for the emergence of subjectivities, not the rearrangement of existing spatiotemporal controls.

This paper is intended as an exposition of the four conceptual overlays for soundscape design, rather than being a discussion of their practical synthesis in soundscape installations. However, some examples of works created by sound artists 
and soundscape designers, which the author suggests are commensurate with the intentions of the conceptual overlays, have been referred to throughout the paper. Max Neuhaus' Times Square (see note 18), Bill Fontana's White Sound - An Urban Seascape ${ }^{25}$ and Bruce Odland and Sam Auinger's Harmonic Bridge (see note 19) are public soundscape installations that repattern (and thus transform) site-specific sounds. In so doing the system of signs (as signified by site-specific sounds) is challenged in which a-signifying ruptures afford the emergence of new natures. It is listener immersion within these new natures that affords the emergence of subjectivities. The author has also realised soundscape designs in accordance with the conceptual overlays, including Revoicing the Striated Soundscape in which readymade air conditioners played resynthesised site-specific sounds to reimpart smooth space in the striated spaces of the city (striated by the broadband drones of air conditioners) and to subvert the isorhythmic refrain (the repetitive rhythms of everyday sounds in space) for the emergence of new natures. ${ }^{26}$

\section{Conclusion}

Arendt, Deleuze and Guattari, and Lefebvre determine art in public spaces as capable of challenging the homogenising capturing of space and time, and all point to the potential of public art to catalyse repressed subjectivities within the tranquilised urban dweller. Soundscape design, as public art, plays a unique role in providing lines of flight from captured space and disassembling controls within space; in particular, it is the amorphous character of sound that characterises its potential to affect immediate change. Public art acts as an a-signifying rupture that generates diverse social spaces through the emergence of multiplicities of subjectivities, which act simultaneously collectively and heterogeneously, with each expressing the rupture as differentiated lived experiences. Urban soundscape design has a unique place in the potential of public art to affect change through the a-signifying rupture due to the reservoir of potential inherent in urban sounds. The catalysing of creative and diverse experiences in urban spaces becomes comparative in effect to the diverse experiences afforded by nature (particularly wilderness). In this way soundscape design affects transformations of functionalised (or captured) urban spaces into new natures. It is the breaking down, catalysing and transforming of captured space and time, particularly as rhythms, that is the emergence of new natures from the sonic potential of urban spaces. The creative act of soundscape design is able to desynchronise isorhythmic refrains and reimpart the smooth within the striated for the creation of new natures within urban spaces. The intent of the four conceptual overlays is to render sociopolitical understandings of the city to which the soundscape designer responds with the creation of public soundscape installations. It is argued that soundscape installations that are designed to 
respond to site-specific sounds (by repatterning the urban soundscape) are particularly effective in subverting spatiotemporal controls and disassembling collective assemblages of enunciation for the diversification of urban dwellers' subjective experiences of the city.

\section{References}

Arendt, Hannah (1998 [1958]). The Human Condition. Chicago and London: The University of Chicago Press.

Aronowitz, Stanley (2007). The Ignored Philosopher and Social Theorist: on the Work of Henri Lefebvre. Situations Journal, 2(1), 133-155.

Augoyard, Jean-Francois, \& Torgue, Henry (2005 [1995]). Sonic Experience: A Guide to Everyday Sounds. Trans. McCartney, Andrea, \& Paquette, David. Canada: McGill-Queen's University Press.

Beatley, Timothy (2011). Biophilic Cities: Integrating Nature into Urban Design and Planning. Washington, DC: Island Press.

Deleuze, Gilles, \& Guattari, Felix (2004 [1987]). A Thousand Plateaus: Capitalism and Schitzophrenia. Trans. Massumi, Brian. London \& New York: Continuum International Publishing Group.

Elden, Stuart (2004). Between Marx and Heidegger: Politics, Philosophy and Lefebvre's The Production of Space. Antipode, 36(1), 86-105.

Elden, Stuart (2004). Understanding Henri Lefebvre: theory and the possible. London \& New York: Continuum.

Foucault, Michel (1977). Language, Counter-Memory, Practice: Selected Essays and Interviews. New York: Cornell University Press.

Fry, Karin A. (2009). Arendt: a guide for the perplexed. New York: Continuum.

Goodman, Steve (2010). Sonic Warfare: Sound, Affect and the Ecology of Fear. USA: The MIT Press.

Guattari, Felix (2008 [1989]). The Three Ecologies. London and New York: Athelone Press.

Hellstrom, Bjorn (2012). Acoustic Design Artifacts and Methods for Urban Soundscapes: a Case Study on the Qualitative Dimensions of Sounds. In: Internoise 2012, New York, August 19-22, 2012. Accessed 28 January 2014 on: http://www.acousticdesign.se/upload/files/InterNoise_NY_ Paper.pdf

Kreutzfeldt, Jacob (2012). Street Cries and the Urban Ritornelle. Sound Effects: An Interdisciplinary Journal of Sound and Sound Expereince, 2(1), 61-80.

LaBelle, B. (2006). Background Noise: Perspectives on Sound Art. New York: Continuum.

Lacey, Jordan (2014) Site-Specific Soundscape Design for the Creation of Sonic Architectures and the Emergent Voices of Buildings, Buildings, 4, 1-24.

Lacey, Jordan. 2013. "Designing Urban Soundscapes for the Effects of Nature", in Davis, S. (eds) Balance-Unbalance Future Nature: Future Culture(s), Noosa, Australia, May 31 - June 2, 2013, pp. 122-133. ISBN: 978-1-921047-73-2.Lacey, Jordan (2012a) Biophilic Sound Design in the Second Order of Nature. Soundscape: The Journal of Acoustic Ecology, 11(1), 24-7.

Lacey, Jordan (2012b) Revoicing the Urban Soundscape: a Case Study of Soundscape Design Interventions at RMIT University. Cumulus Helsinki Northern World Mandate Conference, Helsinki, Finland, 24-26 May 2012, Conference. http://cumulushelsinki2012.org/cumulushelsinki2012.org/ wp-content/uploads/2012/05/Revoicing-the-Urban-Soundscape.pdf (accessed on 13th April 2014).

Lacey, Jordan and Harvey, Lawrence (2011a) Sound Cartography Approaches to Urban Soundscape Research: Citysounds and Sites-of-Respite in the City of Melbourne in Caquard, S. Vaughan, L. and Cartwright, W (eds) Mapping Environmental Issues in the City: Arts \& Cartography Cross-Perspectives, 1st edition, Springer, 246-265. 
Lacey, Jordan. and Harvey, Lawrence (2011b) Pre-modern design of post-natural soundscapes", Kerb19 Journal of Landscape Architecture - Paradigms of Nature: Post-Natural Futures, 114-119.

Lefebvre, Henri (1991 [1974]). The Production of Space. Trans. Nicholson-Smith, D. Malden, MA and Oxford, UK and Carlton, Victoria: D. Blackwell Publishing Limited.

Lefebvre, Henri (2004 [1992]). Rhythmanalysis: space, time and everyday life. Trans. Elden, S. London and New York: Continuum International Publishing Group.

Morton, Timothy (2007). Ecology Without Nature. USA: Harvard University Press.

Russolo, Luigi (1967[1913]). The Art of Noises. West Glover Vermont: Something Else Press.

Schafer, Murray (1977). The Soundscape. Canada: Destiny Books.

Schafer, Murray (1993). Voices of Tyranny Temples of Silence. Canada: Arcana Editions.

Tinnell, John C. (2012). Transversalising the Ecologcial Turn: Four Components of Felix Guattari's Ecosophical Perspective. Deleuze Studies, 6(3), 357-388.

\section{Notes}

1 R. Murray Schafer is the founder of the Acoustic Ecology movement, which tends to favour environmental sound over urban sound and was founded upon the belief that urban noise is an environmental health issue (Schafer, 1997, p. 181-202). This position has been criticised (not unfairly) as moralistic, judgmental and romantic (see, for example, Hellstrom, 2003, p. 20). However, it is beyond dispute that Schafer's work has been instrumental in raising soundscape awareness internationally. The existence of the WFAE is testimony to this (see http:// wfae.proscenia.net/).

2 Soundscape remains a useful umbrella term for discussing the sounds of the environment and creative approaches to urban design. While the term soundscape is used in regard to the described soundscape practice, sound effect is equally applicable terminology.

3 Here I am referring to the co-authored philosophies of Deleuze and Guattari. At times I will refer to them individually.

4 See Lacey (2012b).

5 For more information, see: http://goo.gl/CqZhh.

6 See Lacey (2011b).

7 Throughout this paper the creative practitioner is referred to as a soundscape designer, which is in keeping with the author's practice. However, the soundscape designer could also be considered a soundscape artist, sound artist or simply an artist. This is not to suggest that there is no difference between these terms, only that in the opinion of the author, the comments of philosophers quoted throughout this paper equally apply to all of these terms.

8 In his introduction to Deleuze's Spinoza, Robert Hurley writes, 'this book on Spinoza is difficult. But the situation is helped by the author's word to the wise: one doesn't have to follow every proposition, make every connection-the intuitive or affective reading may be more practical anyway. What if one accepted the invitation-come as you are-and read with a different attitude, which might be more like the way one attends to poetry?' (Deleuze, 1988, p. iii). In the author's opinion, Hurley's advice can be extended to the philosophies of Deleuze and Guattari that are referred to in this paper.

9 For example, Steve Goodman (2010) preferences Deleuze's Spinozian argument for a 'nonanthropocentric notion of a body' in which a body can be made up of anything (p. 100). Goodman contrasts this non-anthropomorphic approach with Augoyard and Torgue's (see bibliography) approach to understanding urban sound, which he describes as 'a phenomenology of sonic perception in which human audition is given primacy' (p. 46). This, in Goodman's opinion, is less preferable than an 'environmentality of affects', which is a Deleuzian consideration that 'rests on an ontology of vibrational force in which a body becomes merely 
another actual entity in a vibrational event, assuming not necessarily any more significance than the resonances between other entities within this nexus' (p. 46).

10 It is worth noting that the author has also considered non-anthropomorphic approaches to soundscape design, particularly in regard to the description of a soundscape design methodology based on pantheistic considerations. See Lacey (2014).

11 For further discussion, see Guattari, 2008, p. 40.

12 For example, Timothy Morton (2007) convincingly argues that Nature is a non-existent romantically aestheticised image that distracts us from our immediate ecologies, that is, the spaces in which we live (p. 114, 202-205).

13 Guattari was a psychotherapist, though there can be little doubt of his philosophical credentials.

14 Though subversive methods are by no means easy options, with perhaps the exception of strikes or the more recent phenomena of flash mobs. See http://six.fibreculturejournal.org/ fcj-030-flash-mobs-in-the-age-of-mobile-connectivity/ for a conversation of Deleuze and Guattari's relationship to this phenomenon.

15 At the time of writing, developers in the Australian state of Victoria were being granted access to build accommodation in national parks, once sacrosanct spaces free from development. This is further demonstration of Lefebvre's observation of capitalism's ability to reinvent itself through the production and domination of space. One may think it is only a matter of time before the deep sea and the peaks of mountaintops are colonised. See http://www.theage. com.au/environment/national-parks-to-be-opened-up-for-development-20120823-24o1q. html.

16 For further discussion on the relationships between urban sounds and the refrain, see Jacob Kreutzfeldt's (2012) recent article which 'seeks to outline a fertile area of study for sound studies: the investigation of everyday refrains and the environmental relations they express and perform' (p. 1).

17 This warrants comparisons with Deleuze's Difference and Repetition, which discusses the repetition of the same in daily life, or habitus, as forming our sense of the real. However, this is the extent of this paper's comparison with Difference and Repetition. Specifically, The Refrain is utilized in this paper as a concept to understand repetition in the conceptual overlay The Isorhythmic Refrain, and the creation of differential experiences as reterritorialisations caused by public soundscape installations. The conversation of difference-in-itself in Difference and Repetition is another discussion altogether.

18 This conjecture resonates with Steve Goodman's (2010) reflection that Lefebvre's explorations of rhythmanalysis were overly 'concerned by the equilibrium of rhythmic systems, by their harmonization in a hierarchy of instants' (p. 8).

19 Bruce Odland and Sam Auinger's 'harmonic bridge' could be described as a eurhythmic soundscape installation in which the drones of traffic are transformed into a harmonic structure. See http://vimeo.com/71463497.

20 The sound artist Max Neuhaus' sound installation, Times Square, references on-site sounds to manifest diverse tonalities without rhythmic (temporal) reference (See Labelle, 2006, p. 156-158 for further discussion). A short film describing the installation can be accessed here: http://www.max-neuhaus.info/timessquare.htm (accessed on 28 January 2014).

21 The Muzak Corporation has a website that divides music into categories suitable for the soundscapes of different businesses. This demonstrates the ability of refrains to striate space (in the sense of zoning and determining experience) by sonic means. See: http://www.muzak. com/products/music.

22 As discussed in footnotes 11 and 15, Max Neuhaus and Bill Fontana provide examples of the potential to reterritorialise space with public soundscape installations that reference sitespecific sounds. However, the terms are equally useful for indoor and/or private settings. 
For example, Alvin Lucier's Sitting in a Room is an indoor-based sound installation in which a repetitive motif of a speaking voice, generated with the use of tape recorders, amplifiers, speakers and microphone, takes on the characteristics of the resonant frequencies of a room. The repeating voice can be considered a refrain that reterritorialises space with each repetition (see LaBelle, 2006, p. 123-132 for further discussion). Agostino Di Scipio, a contemporary composer and sound artist, creates installations and concerts by reworking the acoustic material of a room with microphones and speakers. (See http://agostinodiscipio.xoom.it/ adiscipi/ for more information). Di Scipio's technique can be considered one that challenges the territoriality of site-specific refrains.

23 Indeed, how can nature and culture be considered apart when the remaining 'natural' environments of the Western world are controlled by the state apparatus and reduced to exchange values (number of tourists, park fees, number of species etc.)?

24 Such spaces are ever diminishing, with the lines of flight from the controlled spaces of the urban to the codeless spaces of wilderness ensuring its speedy destruction - such as the surge in tourism to Antarctica.

25 In this work the sound artist Bill Fontana introduces a live recording from a seaside location into an urban space dominated by traffic sounds. This creates ambiguous listening experiences in which the typical sounds of traffic are transformed by live recordings of breaking waves, which contain similar sonic qualities to the passing traffic. For a listening example see: http://resoundings.org/Pages/WHITE_SOUND2.html (accessed on 28 January 2014).

26 See http://www.vic.gov.au/event/2012/07/revoicing-the-striated-soundscape.html for an explanation of the work. And http://hiddensounds.bandcamp.com/album/air-re-conditioners to hear sound examples (accessed on 31 January 2014). 